\title{
Cultivo de melão rendilhado com dois e três frutos por planta
}

\author{
Hamilton César de O Charlo; Renata Castoldi; Pablo F Vargas; Leila T Braz \\ UNESP-FCAV, Dep ${ }^{\text {to }}$ Prod. Vegetal, Rodov. Prof. Paulo Donato Castellane, s/n, 14884-900 Jaboticabal-SP; hamiltoncharlo@gmail.com; \\ rcastoldi@gmail.com; pabloforlanvargas@gmail.com; leilatb@fcav.unesp.br
}

\section{RESUMO}

O objetivo deste trabalho foi avaliar cultivares de melão rendilhado produzidas em plantas sob raleio dos frutos. Foram estudadas as cultivares Maxim, Louis, Fantasy, Shinju 200, e Bônus n², com as plantas conduzidas com dois e três frutos. O delineamento experimental foi em blocos ao acaso, em esquema fatorial $5 \times 2$, com quatro repetições e com as plantas dispostas no espaçamento de 1,0 m entre linhas e $0,5 \mathrm{~m}$ entre plantas. O experimento foi realizado em casa de vegetação, utilizando-se fertirrigação e vasos plásticos de $13 \mathrm{~L}$, preenchidos com fibra da casca de coco Golden Mix ${ }^{\circledR}$ Misto 98 . As mudas foram produzidas em bandejas de poliestireno expandido de 128 células e quando estavam com a primeira folha definitiva completamente desenvolvida foram transplantadas aos vasos. Foram avaliados o rendilhamento da casca, os diâmetros longitudinal e transversal do fruto, o índice de formato do fruto, os diâmetros longitudinal e transversal do lóculo, o índice de formato do lóculo, a espessura do mesocarpo, a massa média dos frutos e a produção por planta. Não houve interação entre os fatores estudados. Nas condições deste experimento, a condução de dois frutos por planta resultou em maior rendilhamento da casca, maior diâmetro transversal do fruto, maior diâmetro longitudinal do lóculo e maior massa média dos frutos. Porém, as maiores produções por planta foram observadas quando conduzidas com três frutos. Os híbridos Fantasy e Shinju 200 apresentaram as melhores características de frutos e maiores produções.

Palavras-chave: Cucumis melo, fibra da casca de coco, raleio de frutos, cultivo sem solo.

\section{ABSTRACT \\ Evaluation of net melon cultivars conducted with two and three fruits per plant}

The pruning of fruits of net melon cultivars was evaluated in this study. The cultivars Maxim, Louis, Fantasy, Shinju 200 and Bônus $\mathrm{n}^{\circ} 2$ were evaluated in plants bearing two and three fruits. The experimental design was of randomized blocks in factorial scheme 5 $\mathrm{x} 2$, with four replications and the plants arranged in the spacing of $1.0 \mathrm{~m}$ between lines and $0.5 \mathrm{~m}$ between plants. The experiment was conducted in greenhouse, using fertirrigation and plastic pots of 13 L, filled with coconut fiber Golden Mix ${ }^{\circledR}$ Misto 98 . The seedlings were grown in expanded polystyrene trays of 128 cells and transplanted to pots when the first definitive leaf was completely developed. We evaluated the roughness of the rind, the longitudinal and transversal diameters of fruits, the fruit shape index, the longitudinal and transversal diameters of the locule, the locule shape index, the thickness of the mesocarp, the average weight of fruits and the production per plant. No interaction between the studied factors was detected. For the conditions of this experiment, the conduction of two fruits per plant generated greater transverse diameter of fruit, greater longitudinal diameter of the locule, greater roundness of the rind and greater average weight of fruits. However, the greatest productions per plant was observed in plants bearing three fruits. The hybrids Fantasy and Shinju 200 presented the best fruit characteristics and greater production.

Keywords: Cucumis melo, coconut fiber, pruning fruit, soilless culture.

\section{(Recebido para publicação em 30 de maio de 2008; aceito em 18 de maio de 2009) (Received in May 30,2008; accepted in May 18, 2009)}

$\mathrm{O}$ melão (Cucumis melo) é uma hortaliça que teve seu cultivo comercial iniciado no Brasil na década de 60, e desde então, vem ganhando em importância econômica. Há seis grupos botânicos, entre os quais, o Cantaloupensis, ao qual pertence o melão rendilhado (Cucumis melo var. cantalupensis Naud.) (Rizzo, 1999). O Brasil é o sexto maior exportador mundial de melão, o que corresponde a cerca de $7 \%$ do mercado. Foram produzidos no Brasil em 2005, 190 mil toneladas de melões (FAO, 2006), com fortes tendências de crescimento, em função do consumo interno e das exportações. As exportações tiveram crescimento de $116 \%$ entre 1997 e 2002, passando de
45,7 mil toneladas em 1997 para 98,7 mil toneladas em 2002, correspondendo a US\$37,8 milhões (Freitas et al., 2004).

Dentre os melões produzidos no Brasil, o rendilhado apresenta algumas vantagens comerciais, tais como, preferência pelo consumidor, boa cotação comercial e cultivo em pequenas áreas, com boa lucratividade (Rizzo \& Braz, 2004). O consumo de melão rendilhado está relacionado ao teor de sólidos solúveis, que contribuem para o sabor; ao aspecto visual, que o diferencia dos outros tipos de melões e, a qualidade nutricional, pois é boa fonte de betacaroteno (Lester, 1997).

Segundo Carrijo et al. (2004), a crescente demanda por hortaliças de alta qualidade e ofertadas durante o ano todo tem contribuído para o investimento em novos sistemas de cultivo, que permitam produção adaptada a diferentes regiões e condições adversas do ambiente.

Entre os componentes de formação da produtividade e da qualidade do meloeiro, tem-se o número de frutos por planta. De acordo com Costa et al. (2004), o número de frutos por planta e a disponibilidade de potássio são dois fatores relativos ao manejo cultural com potencial efeito sobre a qualidade dos frutos de meloeiro, uma vez que podem alterar a razão área foliar por fruto, ou seja, modifica a relação fonte-dreno. 
Martins et al. (1998) e Monteiro \& Mexia (1988) relatam que, normalmente em cultivo de meloeiro em casa de vegetação (condução da planta na vertical tutorada e podada), as plantas conseguem desenvolver dois frutos, haja vista a ocorrência de abortamento natural pela planta. Farias et al. (1988) também constataram que neste sistema de condução, somente dois ou três frutos atingem o estádio de maturação.

São escassos na literatura dados sobre a condução do meloeiro rendilhado cultivado em substratos. Portanto, neste trabalho foi avaliada a produção de cultivares de melão rendilhado conduzidos com dois ou três frutos por planta.

\section{MATERIAL E MÉTODOS}

O experimento foi conduzido em casa de vegetação da UNESP em Jaboticabal, de 4 de novembro de 2005 a 15 de fevereiro de 2006. Foram avaliados cinco híbridos comerciais de melão rendilhado (Maxim, Bônus n², Shinju 200, Fantasy e Louis) conduzidos com dois ou três frutos por planta. $O$ delineamento experimental foi de blocos ao acaso, em esquema fatorial $5 \times 2$, com quatro repetições.

A semeadura foi realizada manualmente, em bandejas de poliestireno expandido de 128 células, preenchidas com substrato Plantmax $\mathrm{HT}^{\circledast}$. Dez dias após a semeadura, quando as mudas estavam com a primeira folha definitiva formada, foi realizado o transplante para os vasos plásticos de $13 \mathrm{~L}$ contendo fibra da casca de coco Golden Mix ${ }^{\circledR}$ Misto 98, cujas características físicas são porosidade total $=94 \%$; capacidade de aeração= $35 \%$; capacidade de retenção de água disponível $=41 \%$ (Amafibra, s.d.). As características químicas da fibra são $\mathrm{pH}=5,1$; condutividade elétrica $=1,0$ $\mathrm{dS} \mathrm{m}^{-1} ; \mathrm{N}$-nitrato $=8,1 \mathrm{mg} \mathrm{L}^{-1}$; fósforo $=53,0 \mathrm{mg} \mathrm{L}^{-1}$; cloreto $=44,6 \mathrm{mg} \mathrm{L}^{-1}$; enxofre $=92,1 \mathrm{mg} \mathrm{L}^{-1} ; \mathrm{N}$-amônia $=17,7$ $\mathrm{mg} \mathrm{L}^{-1}$; potássio $=270,1 \mathrm{mg} \mathrm{L}^{-1}$; sódio $=$ $12,6 \mathrm{mg} \mathrm{L}^{-1}$; cálcio $=9,9 \mathrm{mg} \mathrm{L}^{-1}$; magnésio $=6,6 \mathrm{mg} \mathrm{L}^{-1}$; boro $=0,5 \mathrm{mg} \mathrm{L}^{-}$ ${ }^{1}$; cobre $=0,1 \mathrm{mg} \mathrm{L}^{-1}$; ferro $=0,4 \mathrm{mg} \mathrm{L}^{-1}$; manganês $=0,1 \mathrm{mg} \mathrm{L}^{-1}$ e zinco $=0,5 \mathrm{mg}$ $\mathrm{L}^{-1}$. Cada parcela foi constituída de sete plantas, dispostas no espaçamento de $1,0 \mathrm{~m}$ entrelinhas e $0,5 \mathrm{~m}$ entre plantas, sendo avaliadas as cinco centrais.

O tutoramento das plantas foi realizado com fitilhos plásticos, presos a arames localizados rente ao substrato contido no vaso e a dois metros de altura. $\mathrm{O}$ amarrio das plantas foi realizado sempre que necessário. Quando a planta atingia a máxima altura realizava-se a capação, conduzindo-se uma planta por vaso. Após a fixação dos frutos, foram realizadas desbrotas até o décimo nó. A polinização se deu de forma manual. Após o pegamento dos frutos foram realizados raleios sempre que necessário, deixando-se dois ou três frutos por planta de acordo com o tratamento.

A fertirrigação foi por gotejo, adotando-se para a adubação, a solução nutritiva recomendada por Castellane \& Araújo (1994) e, para o controle da quantidade aplicada, a metodologia da drenagem mínima. A aplicação da solução nutritiva foi controlada por um temporizador, tendo início às 7 horas e término às 18 horas, sendo que em todas as horas desse período ocorria a fertirrigação por alguns minutos. No início do cultivo a fertirrigação era feita com quatro minutos por hora, sendo este tempo aumentado com o desenvolvimento da cultura, chegando a 15 minutos no final do ciclo. Foi realizado o controle de pragas e doenças, empregando-se produtos registrados para a cultura e doses recomendadas pelos fabricantes.

Os frutos foram colhidos quando atingiram o máximo do desenvolvimento. Foram avaliados: rendilhamento de casca (RC), adotando a escala de notas $(1=$ muito rendilhado; $2=$ medianamente rendilhado e 3= pouco rendilhado); diâmetros longitudinal (DLF) e transversal do fruto (DTF), utilizando paquímetro digital $(\mathrm{cm})$; índice de formato do fruto (IFF), obtido pela relação do diâmetro longitudinal e o transversal do fruto; diâmetros longitudinal (DLL) e transversal do lóculo (DTL), utilizando paquímetro digital (mm); índice de formato do lóculo (IFL), obtido pela rela- ção do diâmetro longitudinal e o transversal do lóculo; espessura do mesocarpo (EM), utilizando paquímetro digital; massa do fruto (MF) e produção por planta (PP).

Os dados foram submetidos à análise de variância e quando observou-se significância pelo teste $\mathrm{F}$, em função de cultivares e número de frutos por planta, as médias foram submetidas ao teste de Tukey, ao nível de 5\%. Utilizou-se o programa estatístico Estat, Sistemas para Análises Estatísticas versão 2.0, desenvolvido pela UNESP/FCAVJaboticabal.

\section{RESULTADOS E DISCUSSÃO}

Não se verificaram interações significativas entre as cultivares e número de frutos por planta (Tabela 1) para as características avaliadas, mas sim efeito dos fatores isoladamente.

Analisando a característica rendilhamento de casca, observou-se diferença significativa entre as cultivares e entre número de frutos por planta. $\mathrm{O}$ híbrido Bônus $\mathrm{n}^{\circ} 2$ apresentou melhor rendilhamento de casca $(1,05)$, diferindo apenas do híbrido Fantasy (Tabela 1). Quando a planta foi conduzida com três frutos, o rendilhamento da casca foi influenciado negativamente, ou seja, os frutos apresentaram-se menos rendilhados quando comparados àqueles provenientes de plantas com apenas dois frutos. No entanto, a média de rendilhamento de 1,3 pode ser considerada boa, e neste caso os frutos seriam bem aceitos no mercado. Vale ressaltar que o rendilhamento da casca é uma das características de maior importância em frutos de melão rendilhado, visto que é um dos atrativos visuais dessa hortaliça aos consumidores (McCreight et al., 1993; Gorgatti Neto et al., 1994; Silva et al., 2000).

Com relação ao diâmetro longitudinal do fruto, não verificou-se diferença entre as cultivares. Já para o fator número de frutos verificou-se que plantas conduzidas com dois frutos proporcionaram maiores médias para esta carac- 
Tabela 1. Características de cinco cultivares de melão rendilhado, em função do número de frutos por planta (characteristics of five net melons cultivars, in function of number of fruit per plant). Jaboticabal, UNESP, 2006.

\begin{tabular}{|c|c|c|c|c|c|c|c|c|c|c|}
\hline $\begin{array}{l}\text { Cultivares } \\
\text { (C) }\end{array}$ & RC & $\operatorname{DLF}(\mathrm{cm})$ & DTF (cm) & IFF & DLL (cm) & DTL (cm) & IFL & $\mathrm{EM}(\mathrm{cm})$ & MF (kg) & $\mathrm{PP}\left(\mathrm{kg} \mathrm{pl}^{-1}\right)$ \\
\hline Maxim & $1,31 a b^{1}$ & $13,16 \mathrm{a}$ & $13,06 a b$ & $1,01 \mathrm{a}$ & $7,82 \mathrm{a}$ & $5,85 a b$ & $1,34 \mathrm{bc}$ & $3,57 \mathrm{a}$ & $1,12 \mathrm{~b}$ & $2,74 \mathrm{~b}$ \\
\hline Louis & $1,21 a b$ & $13,20 \mathrm{a}$ & $12,76 a b$ & $1,03 a$ & $7,84 \mathrm{a}$ & $5,24 \mathrm{c}$ & $1,50 \mathrm{a}$ & $3,84 \mathrm{a}$ & $1,17 \mathrm{~b}$ & $2,87 \mathrm{~b}$ \\
\hline Fantasy & 1,38 a & $13,00 \mathrm{a}$ & $13,47 a$ & $0,96 \mathrm{~b}$ & $7,61 \mathrm{a}$ & $5,88 a$ & $1,29 \mathrm{c}$ & 3,97 a & $1,31 \mathrm{a}$ & 3,23 a \\
\hline Shinju 200 & $1,19 a b$ & $13,12 \mathrm{a}$ & $12,90 a b$ & $1,02 \mathrm{a}$ & $7,62 \mathrm{a}$ & $5,29 \mathrm{bc}$ & $1,45 a b$ & $3,59 a$ & $1,19 a b$ & $2,96 a b$ \\
\hline Bônus $n^{\circ} 2$ & $1,05 \mathrm{~b}$ & $13,10 \mathrm{a}$ & $12,53 b$ & $1,05 a$ & $7,63 \mathrm{a}$ & $5,44 a b c$ & $1,41 \mathrm{abc}$ & $3,64 \mathrm{a}$ & $1,08 \mathrm{~b}$ & $2,67 \mathrm{~b}$ \\
\hline \multicolumn{11}{|c|}{$\mathrm{N}^{\circ}$ frutos (NF) } \\
\hline Dois frutos & $1,15 b$ & $13,45 \mathrm{a}$ & $13,24 \mathrm{a}$ & $1,02 \mathrm{a}$ & $7,91 \mathrm{a}$ & $5,68 \mathrm{a}$ & $1,40 \mathrm{a}$ & $3,82 a$ & $1,25 a$ & $2,50 \mathrm{~b}$ \\
\hline Três frutos & $1,30 \mathrm{a}$ & $12,79 \mathrm{~b}$ & $12,65 \mathrm{~b}$ & $1,01 \mathrm{a}$ & $7,50 \mathrm{~b}$ & $5,40 \mathrm{~b}$ & $1,39 \mathrm{a}$ & $36,26 \mathrm{~b}$ & $1,10 \mathrm{~b}$ & $3,29 a$ \\
\hline $\mathrm{F}(\mathrm{C} \times \mathrm{NF})$ & $0,87 \quad$ NS & $2,15^{\mathrm{NS}}$ & $0,48 \quad \mathrm{NS}$ & $1,22 \mathrm{NS}$ & $1,43^{\mathrm{NS}}$ & $0,62 \mathrm{NS}$ & $0,70^{\mathrm{NS}}$ & $0,46 \quad \mathrm{NS}$ & 1,26 NS & 1,84 NS \\
\hline$\overline{C V}(\%)$ & 17,39 & 3,93 & 4,10 & 2,89 & 6,03 & 7,08 & 6,08 & 7,53 & 7,17 & 7,49 \\
\hline
\end{tabular}

$\mathrm{RC}=$ rendilhamento da casca $(1=$ muito rendilhado; $2=$ medianamente rendilhado e $3=$ pouco rendilhado); DLF= diâmetro longitudinal do fruto; $\mathrm{DTF}=$ diâmetro transversal do fruto; $\mathrm{IFF}=$ índice de formato do fruto; DLL= diâmetro longitudinal do lóculo; DTL= diâmetro transversal do lóculo; $\mathrm{IFL}=$ índice de formato do lóculo; $\mathrm{EM}=$ espessura do mesocarpo; $\mathrm{MF}=$ massa do fruto; $\mathrm{PP}=$ produção por planta $(\mathrm{RC}=$ roughness of the rind ( $1=$ very rough; $2=$ medium roughness and $3=$ poor roughness); $\mathrm{DLF}=$ longitudinal diameter of fruit; $\mathrm{DTF}=$ transverse diameter of fruit; $\mathrm{IFF}=$ fruit shape index; $\mathrm{DLL}=$ longitudinal diameter of locule; $\mathrm{DTL}=$ transverse diameter of locule; $\mathrm{IFL}=$ locule shape index; $\mathrm{EM}=$ thickness of the mesocarp; $\mathrm{MF}=$ weight of fruits; $\mathrm{PP}=$ production per plant).

${ }^{1}$ Médias seguidas pela mesma letra minúscula, na coluna, não diferem significativamente, ao nível de 5\% de probabilidade, pelo teste de Tukey. (average values followed by same letter in column don't differ significantly at 5\% level of probability by Tukey test).

terística (13,45 cm). Rizzo \& Braz (2004) verificaram valores para esta característica variando de 9,20 a $13,10 \mathrm{~cm}$, em pesquisa nas quais as plantas foram conduzidas com dois frutos por planta.

Quanto ao diâmetro transversal do fruto (DTF), observa-se que a cultivar Fantasy apresentou maior valor $(13,47$ $\mathrm{cm})$, diferindo estatisticamente apenas da cultivar Bônus no 2 (12,53 cm), sendo que plantas conduzidas com dois frutos apresentaram maior diâmetro transversal do fruto $(13,23 \mathrm{~cm})$ do que plantas conduzidas com três frutos $(12,65 \mathrm{~cm})$. Os valores do presente trabalho foram superiores aos verificados por Rizzo \& Braz (2001) que, avaliando cultivares de melão rendilhado conduzido com três frutos por planta, em casa de vegetação, observaram diâmetro transversal de frutos variando de $8,52 \mathrm{~cm}$ na cultivar Hales Best Jumbo a 10,48 cm na cultivar Bônus n²

De maneira geral, o tamanho dos frutos observados no presente trabalho foi superior aos relatados em pesquisas com melão rendilhado, independente das plantas serem conduzidas com dois ou três frutos. Isso demonstra que a utilização de tecnologias mais avançadas, como é o caso do cultivo em fibra de coco, aliada a adequada condução das plantas gera frutos de melhor qualidade e maior produtividade.

O menor índice de formato do fruto foi observado para o híbrido Fantasy $(0,96)$, o que significa que os frutos dessa cultivar têm a tendência de serem mais achatados. Existem mercados para todos os formatos de fruto (Pádua, 2001), mas o esférico é o que mais facilita o arranjo dos frutos nas embalagens utilizadas atualmente (Rizzo \& Braz, 2004). Observa-se que independente do número de frutos por planta, o índice de formato do fruto não se alterou (Tabela 1).

Para o diâmetro longitudinal do lóculo não se verificou diferença significativa entre as cultivares; no entanto, plantas cultivadas com dois frutos apresentaram valores mais elevados para tal característica $(7,91 \mathrm{~cm})$.

A cultivar Louis apresentou o menor diâmetro transversal do lóculo $(5,24 \mathrm{~cm})$, o qual não diferiu das cultivares Shinju 200 e Bônus n 2 com 5,29 cm e 5,44 cm, respectivamente (Tabela 1). Esta é uma característica definida geneticamente e pouco influenciada pelo ambiente e que deve ser levada em conta nos trabalhos de desenvolvimento de cultivares de melão rendilhado pois, como é sabido, quanto menor o diâmetro do lóculo maior a resistência do fruto ao transporte. Além disso, frutos com menor cavidade interna são mais apresentáveis visualmente e mais aceitos pelos consumidores.

$\mathrm{O}$ menor diâmetro longitudinal e transversal do lóculo em frutos provenientes de plantas conduzidas com três frutos (Tabela1) pode estar relacionado ao fato de os frutos dessas plantas serem menores e, consequentemente, com diâmetros de lóculos menores. Apesar de serem dimensionalmente menores apresentam alta qualidade, pois menores valores de diâmetro longitudinal e transversal do lóculo indicam dimensões de cavidade interna menores, e segundo Costa \& Pinto (1977), frutos com menor cavidade interna apresentam maior resistência ao transporte e vida útil pós-colheita prolongada.

A espessura do mesocarpo foi semelhante entre cultivares, mas foi maior em frutos provenientes de plantas conduzidas com dois frutos (Tabela 1). Isto se deve ao fato de que nestas plantas os fotoassimilados produzidos na fotossíntese foram divididos por apenas dois frutos. Como o mesocarpo é a parte comestível dos frutos de melão, quanto mais espesso maior será a valorização. As médias encontradas neste trabalho para esta característica são superiores 
às encontradas na literatura, tanto para dois quanto para três frutos por planta. Pádua (2001), cultivando melão rendilhado em diferentes substratos (solo, areia e substrato comercial) observou na cultivar Bônus $\mathrm{n}^{\circ} 2$, espessura do mesocarpo de $18,2 \mathrm{~mm}$ no verão e $18,78 \mathrm{~mm}$ no inverno. Esta diferença provavelmente está relacionada ao fato da fibra de coco, usada neste trabalho, ser um material esterilizado, diminuindo a incidência de pragas e doenças. Além disso, este material tem baixa CTC, fazendo com que não ocorra adsorção dos nutrientes aplicados; assim, eles ficam prontamente disponíveis às plantas, o que consequentemente proporcionam um maior desenvolvimento da planta e frutos com melhores características. Outro fato que pode explicar esta diferença é que Pádua (2001) conduziu plantas com 3 a 4 frutos, o que certamente fez com que esta característica fosse afetada negativamente, pois a razão fonte/ dreno fora mais elevada que no presente trabalho.

A cultivar Fantasy foi superior a todos os outros híbridos $(1,31 \mathrm{~kg})$, não diferindo estatisticamente apenas da cultivar Shinju 200 (1,19 kg), quando analisada a massa média dos frutos, sendo que quando a planta foi mantida com dois frutos, estes apresentaram maior massa (1,25 kg). Provavelmente os maiores valores de massa média dos frutos das cultivares Fantasy e Shinju 200 sejam devido à superioridade genética em relação às demais cultivares testadas, principalmente devido ao vigor híbrido proporcionado pelo cruzamento de dois parentais com alta capacidade específica de combinação (Tabela 1). Os trabalhos de melhoramento genético de hortaliças são bastante dinâmicos e a cada ano são lançados no mercado novos materiais, sendo estes cada vez mais produtivos e exigentes em técnicas de cultivo. Portanto, trabalhos de avaliação de cultivares são importantes para que sirvam de subsídio aos produtores na tomada de decisão para escolha da cultivar.

As massas médias de frutos observadas nesta pesquisa são superiores às observadas por outros pesquisadores que avaliaram o meloeiro rendilhado em outros sistemas de cultivo e com outras cultivares. Rizzo \& Braz (2001) verificaram para a cultura do melão rendilhado conduzido sob ambiente protegido massa média de fruto de $0,35 \mathrm{~kg}$ no híbrido Aragon a 0,69 kg para o híbrido Bônus $\mathrm{n}^{\circ} 2$. Costa et al. (2003), avaliando o raleio de frutos em melão rendilhado cv. Bônus $\mathrm{n}^{\circ} 2$, em sistema hidropônico fechado, verificaram massa média de frutos de $0,66 \mathrm{~kg}$ quando conduzidos dois frutos por planta e $0,60 \mathrm{~kg}$ quando conduzidos três frutos por planta.

As maiores produções por planta ocorreram nos híbridos Fantasy e Shinju 200 (Tabela 1). Considerandose a área útil por planta de $0,5 \mathrm{~m}^{2}$, a produtividade em $1 \mathrm{~m}^{2}$ seria de $6,46 \mathrm{e}$ $5,92 \mathrm{~kg} \mathrm{~m}^{2}$, valores estes superiores aos observados por Pádua (2001) e Rizzo \& Braz (2004). A maior produção por planta foi observada quando conduziram-se as plantas com três frutos (Tabela 1). A condução de três frutos por planta aumenta a produção, praticamente sem afetar a massa dos frutos. As produções obtidas neste trabalho são maiores do que as de Purquerio et al. (2003), que avaliando os efeitos da concentração de nitrogênio na solução nutritiva e o número de frutos por planta, verificaram que a produção por planta do híbrido Bônus $\mathrm{n}^{\circ} 2$ foi de $2,04 \mathrm{~kg}$ planta ${ }^{1}$ e $1,67 \mathrm{~kg}$ planta $^{-1}$ quando conduzidos dois e três frutos por planta, respectivamente.

Com base nos resultados obtidos, para o cultivo em ambiente protegido em Jaboticabal, indicam-se as cultivares de melão rendilhado Fantasy e Shinju 200, conduzidos com três frutos por planta.

\section{REFERÊNCIAS}

AMAFIBRA - Fibras e Substratos Agrícolas da Amazonia LTDA. s.d.. Fibra de coco. Holambra-SP.

CARRIJO OA; VIDAL MC; REIS NVB; SOUZA RB; MAKISHIMA N. 2004. Produtividade do tomateiro em diferentes substratos e modelos de casas de vegetação. Horticultura Brasileira 22: 5-9.

CASTELLANE PD; ARAÚJO JAC. 1994. Cultivo sem solo: Hidroponia. Jaboticabal: FUNEP. 43p.
COSTA CC; CECÍLIO FILHO AB; CAVARIANI RL; BARBOSA JC. 2003. Produção do melão rendilhado em função da concentração de potássio na solução nutritiva e do número de frutos por planta. Horticultura Brasileira 22: 23-27.

COSTA CC; CECÍlIO FILHO AB; CAVARIANI RL; BARBOSA JC. 2004. Concentração de potássio na solução nutritiva e a qualidade e número de frutos de melão por planta em hidroponia. Ciência Rural 34: 731-736.

COSTA CP; PINTO CABP. 1977. Melhoramento de hortaliças. Piracicaba: ESALQ. 319p.

FARIAS JRB; MARTINS SR; FERNANDES HS. 1988. Comportamento do meloeiro cultivado em estufa plástica, em diferentes espaçamentos e cobertura do solo. Horticultura Brasileira 6: 52.

FAO - FOOD AGRICULTURAL ORGANIZATION. 2006, 3 de novembro. Statistical: database. Disponível em http:// www.apps.fao.org.

FREITAS JAD; LIMA JR; NASSU RT; FILGUEIRAS HAC; BASTOS MSR; SILVA EO; ALVES RE; MORETTI CL; PINHEIRO NETO LG. 2004, 14 de outubro. Manual de boas práticas agrícolas para a cultura do meloeiro $(B P A)$ Disponível em http:// www.cnpat.embrapa.br/upds/frutas/ cap1.pdf.

GORGATTI NETO A; GAYET JP; BLEINROTH EW; MATALLO M; GARCIA EEC; GARCIAAE; ARDITO EFG; BORDIN MR. 1994. Melão para exportação: procedimentos de colheita e pós-colheita. Brasília: EMBRAPA-SPI. $37 \mathrm{p}$.

LESTER G. 1997. Melon (Cucumis melo L.) fruit nutritional quality and health functionality. HortTech 7: 222-227.

MARTINS SR; PEIL RM; SCHWENGBER JE; ASSIS FN; MENDEZ MEG. 1998. Produção de melão em função de diferentes sistemas de condução de plantas em ambiente protegido. Horticultura Brasileira 16: 24-30.

McCREIGHT JD; NERSON H; GRUMET R. 1993. Melon. In: KALLOO G; BERGH BO (eds). Genetic improvment of vegetable crops. Oxford: Pergamon Press. p.267294.

MONTEIRO AA; MEXIA JJ. 1988. Influência da poda e do número de frutos por planta na qualidade dos frutos e produtividade do melão. Horticultura Brasileira 6: 9-12.

PÁDUA JG. 2001. Cultivo protegido de melão rendilhado em duas épocas de plantio. Jaboticabal: UNESP-FCAV. 108p (Tese doutorado).

PURQUERIO LFV; CECÍLIO FILHO AB; BARBOSA JC. 2003. Efeito da concentração de nitrogênio na solução nutritiva e do número de frutos por planta sobre a produção do meloeiro. Horticultura Brasileira 21: 185-190. 
RIZZO AAN. 1999. Avaliação de caracters agronômicos e qualitativos de cinco cultivares de melão rendilhado (Cucumis melo var. reticulatus Naud.) e da heterose em seus híbridos F1. Jaboticabal: UNESPFCAV. 61p (Tese mestrado).

RIZZO AAN; BRAZ LT. 2001. Características de cultivares de melão rendilhado cultivadas em casa de vegetação. Horticultura Brasileira 19: 370-373.
RIZZO AAN; BRAZ LT. 2004. Desempenho de linhagens de melão rendilhado em casa de vegetação. Horticultura Brasileira 22: 784-788.
SILVA HR; MAROUELLI WA; SILVA WLC; SILVA RA; LEOPOLDO AO; RODRIGUES AG; SOUZA AF; MAENO P. 2000. Cultivo do meloeiro para o Norte de Minas Gerais. Brasília: EMBRAPA. 24p. (Circular Técnica, 20) 